\title{
Development of a device to simulate tooth mobility
}

\author{
Kurt-Jürgen Erdelt* and Timea Lamper \\ Department of Prosthodontics, Ludwig Maximilians \\ University, Munich, Germany
}

\begin{abstract}
Objectives: The testing of new materials under simulation of oral conditions is essential in medicine. For simulation of fracture strength different simulation devices are used for test set-up. The results of these in vitro tests differ because there is no standardization of tooth mobility in simulation devices. The aim of this study is to develop a simulation device that depicts the tooth mobility curve as accurately as possible and creates reproducible and scalable mobility curves.

Materials and methods: With the aid of published literature and with the help of dentists, average forms of tooth classes were generated. Based on these tooth data, different abutment tooth shapes and different simulation devices were designed with a CAD system and were generated with a Rapid Prototyping system. Then, for all simulation devices the displacement curves were created with a universal testing machine and compared with the tooth mobility curve. With this new information, an improved adapted simulation device was constructed.
\end{abstract}

Results: A simulations device that is able to simulate the mobility curve of natural teeth with high accuracy and where mobility is reproducible and scalable was developed.

Keywords: curve of mobility; mobility classes; simulation device; simulation of tooth mobility; tooth mobility.

\section{Introduction}

Testing new dental materials under oral conditions is important before use on a patient [10]. The tests can be done with in vitro simulations. These in vitro tests are also applied on fracture strength of fully anatomical bridges because it is very important to simulate abutment tooth mobility during fracture strength testing $[11,19]$. For simulating abutment tooth mobility different types of testing devices are used for in vitro tests. Alloys, synthetics or removed teeth are used as device abutment tooth materials $[5,8,13,19,20,29,30$,

\footnotetext{
*Corresponding author: Kurt-Jürgen Erdelt, Department of Prosthodontics, Ludwig Maximilians University, Goethestr. 70, 80336 Munich, Germany

Phone: +49-89-5160-9600

Fax: +49-89-5160-9502

E-mail: Kurt.Erdelt@med.uni-muenchen.de
}

$34-36,38,40,42]$. The simplest version of a simulation device is a rigid device of metal or synthetics that is made either with the lost wax technique $[16,24,31]$ or with the help of a computer-aided design (CAD)/computer-aided manufacturing (CAM) or rapid prototyping technique $[4,14$, $18,41]$. The advantage of this type of simulation device is that it can be repeatedly produced in great quantities with constant quality. A drawback is the fact that the abutment teeth are rigidly mounted. The device offers only little mobility which is determined by the Young's modulus of the abutment tooth materials used. If, for example, metal is used, which has a higher Young's modulus than dentin or alveolar bone, the device will show less deformation than physiologically to be expected. This in turn leads to increased fracture loads. The results from such simulation devices are never consistent with actual values gained in in vivo experiments $[3,13,19,20]$. In a flexible simulation device, abutment teeth will be covered with elastic materials such as silicone, synthetic tubes or rubber rings. These materials are used to simulate the movements of the abutment tooth in the periodontal ligament. These abutment teeth will then be casted into a resin composite block [13, 19, 23]. The resulting tooth mobility is low and the degree of mobility cannot be varied. The deflection curves created by this technique do not correspond at all to physiological tooth mobility [21, 25, 33]. In the Regensburg simulation device [36], undamaged removed teeth are surrounded with resin composite and then embedded in a resin composite block. The advantage of this simulation device is the use of human teeth as abutment tooth material, if this is demanded by the study design. However, there are two drawbacks: it is not possible to create a polyether layer with a precisely defined thickness and it is impossible to replicate this simulation device. The displacement curves always vary, as the root geometry and the root surfaces of every natural tooth have individual morphology. The mobility device for front teeth developed in Tübingen [8] shows a clear improvement of the adjustability of physiological tooth mobility: rubber rings are attached to the resin composite abutment tooth and mechanically fastened. Tooth mobility is then adjusted with the use of a Periotest Classic measuring device (Medizintechnik Gulden e. K., Modautal, Germany). However, only roots that are almost round can be simulated and the tooth mobility curves of the devices differ clearly from physiological tooth mobility curves. All simulation devices mentioned above experience the same problems: they simulate the physiological tooth mobility curves only inaccurately and the degree of mobility cannot be adjusted precisely. Therefore, the aim of this paper is to develop a simulation device that depicts the tooth mobility curve $[11,17,21,22,34,44]$ (Figure 1) as accurately as possible and creates reproducible mobility curves, thus making a more reliable prediction of the failure limits of prosthetics possible. 


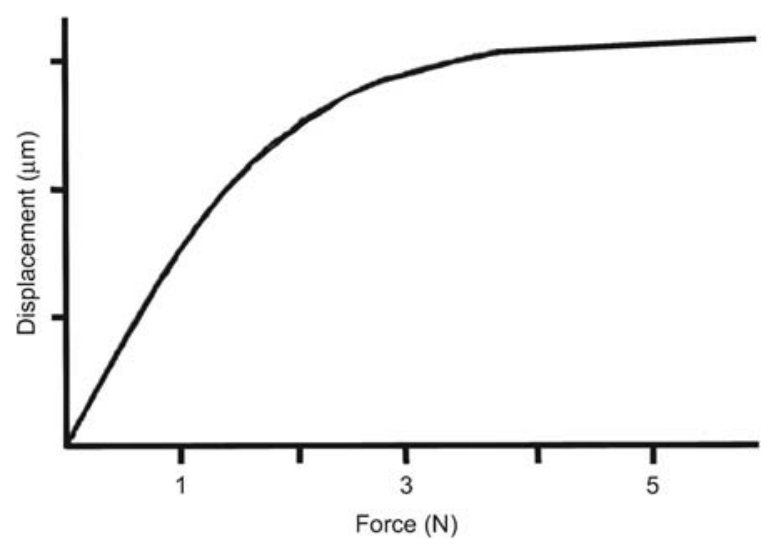

Figure 1 Idealized lateral tooth mobility curve of a natural tooth $[11,17,21,22,25,34,44]$.

\section{Materials and methods}

In the first step, average forms of molars, premolars and front teeth were generated based on published literature $[1,9]$ and advice from dentists and dental technicians of the Ludwig Maximilians University (LMU) Munich. Each tooth class was analyzed and the values of the height, length, width and root of the tooth length were calculated. Based on this data, different abutment tooth shapes and different simulation devices were designed with a CAD system (SolidWorks, Concord, MA, USA).

The abutment teeth differ in the root of the teeth shape and in the position of the center of rotation, and the simulation devices in the size of the gap between the varied abutment tooth shape and the base. The function of the gap is to simulate the periodontal ligament. The production of these abutment tooth shapes and simulation devices was done with a Rapid Prototyping system (Rapid Technologies \& Consulting, Frankfurt, Germany). The produced teeth and simulation devices were processed. The abutment teeth were coated with flexible plastic materials with different Young's modulus and casted in plastic blocks (polymethylmethacrylat). The gaps of the simulation devices were filled with flexible plastic material with different Young's moduli. For all simulation devices the displacement curves were created with the help of a universal testing machine (Roell/Amsel 1450, Ulm, Germany). The displacement curves of the simulation devices were compared with an idealized physiological tooth mobility curve [11, 17, 22, 25, 34, 44] (Figure 1). With this information an improved adapted simulation device was developed by a CAD system (SolidWorks). The parts for the optimized simulation device were machine-made by Firma Gembacher (Bergen, Germany). The base of the simulation device was made with metal, the abutment tooth was made with high-performance polymer plastic (Everest CTemp, KaVo, Biberach, Germany) and the gap was filled with silicone (Xantropren L blau, Heraeus Kulzer GmbH, Hanau, Germany) to simulate the periodontal ligament.

This optimized simulation device fulfilled all required conditions for a device to simulate the tooth mobility curve in in vitro simulations. The required conditions for simula- tion devices include (i) the mobility curve of the simulation device is comparable to the mobility curve of natural teeth [11, 17, 21, 22, 25, 34, 44] (Figure 1); (ii) the simulation device mobility is scalable; and (iii) the simulation device mobility curves are reproducible.

\section{Results}

We developed a device that is able to simulate the mobility of natural teeth with repeatable accuracy. To fulfill the requested conditions, the tooth simulation device has to be divided into several subassembly groups (Figure 2). The following sections describe the subassembly groups that depict the tooth simulation device.

\section{Abutment tooth geometries}

The dentists and dental technicians of the LMU Munich designed an average tooth for every tooth class. The lateral cut of the molars is $11 \mathrm{~mm} \times 10 \mathrm{~mm}$, the diameters of the premolars are $7 \mathrm{~mm}$ and $7.5 \mathrm{~mm}$. The diameter of the front teeth is $6.5 \mathrm{~mm}$. The shape of the teeth is modeled to dentistry directives [21, 22]. To use the abutment tooth in a compression test and pull-out test a ball was fixed on the root of the tooth (Figure 3).

As the measurements of real tooth geometries show great variation, the tooth class geometries just give a rough approximation. However, the calculated values are sufficiently precise for the tooth simulation device.

\section{Reproducibility of mobility}

Because the length of the root of the tooth has an influence on the tooth mobility curve, it was necessary for every tooth class to calculate its own center of rotation. In the literature $[6,21,37,39]$, the center of rotation for roots of the teeth is described at one-third of the length of the root from apex to corona. Therefore, the center of the ball from abutment tooth classes was placed on the center of rotation which lies

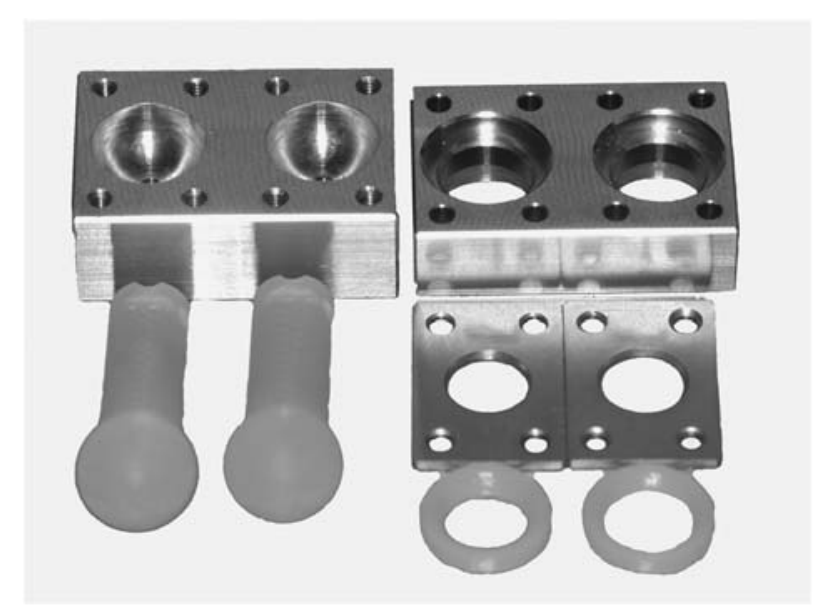

Figure 2 All parts of the Front tooth test device. 


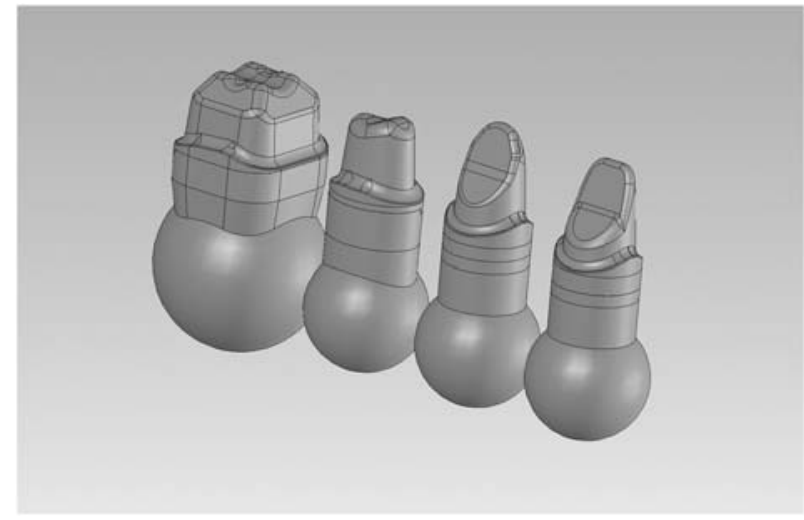

Figure 3 Tooth classes: molar, premolar, canine and incisor with fixed ball.

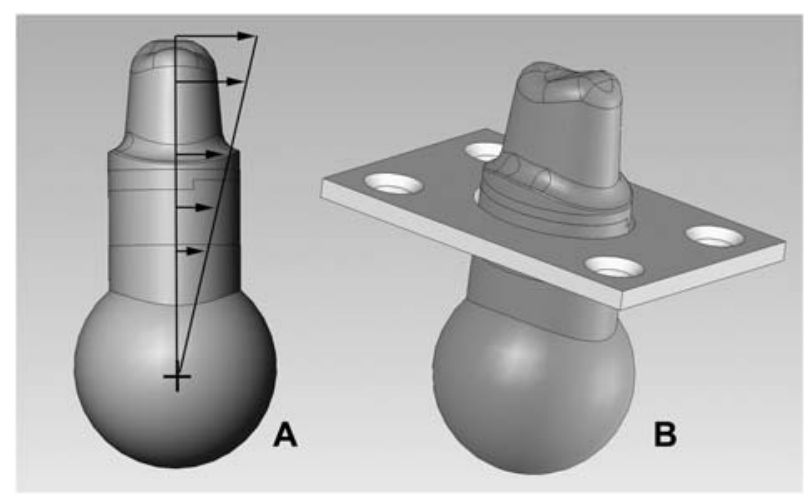

Figure 4 Abutment tooth model: (A) with center of rotation and intercept theorem, (B) with arresting plate.

at approximately one-third of the length of the root of the tooth from apex to corona.

By defining the pivotal point and constructing suitable bearing shells the tooth always moves in the same way during mastication (Figure 4A) [2, 12]. Through this construction we achieve reproducible tooth mobility.

\section{Scalability of mobility}

The simulation of different lateral abutment tooth mobilities was achieved as follows: through a definition of a center of rotation in the abutment tooth it is possible to calculate the line of motion of each individual point on the tooth with the help of the intercept theorem (Figure 4A) [2, 12]. In the mouth the movement of natural teeth is constrained by the jaw bone. To simulate the constraint of the abutment tooth movement in the simulation device, arresting plates with openings of varying size were used (Figure 4B). By varying the gap between the abutment tooth and arresting plate it is possible to adjust the mobility of the abutment tooth. To simulate an additional axial movement, a separation plate of variable thickness was placed between the upper and lower bearing shells and integrated into the simulation device. The arresting plate and the separation plate solved the problem of scalability.

\section{Classes of mobility}

In the created simulation device, the mobility of the abutment tooth is determined by the distance of the arresting plate to the pivotal point and by the gap between the abutment tooth and the arresting plate. It is possible to regulate the abutment tooth mobility in the test set-up with these two parameters. To compare the results of different test set-ups, the mobility of every abutment tooth must be known as accurately as possible. Only in this way can one obtain good measurement. In the relevant literature $[15,21,26,28,43,44]$, there is no precise definition of tooth mobility to be found. Although classifications have been created, these, however, do not provide exact numerical values and therefore allow vast scope for interpretation in the classification of tooth mobility [ 15 , 21, 26, 28, 43]. Through inaccurate classification of tooth mobility in the literature, the measurements of in vitro tests are scarcely comparable. The point of application of force is usually placed just underneath the topmost point of the crown. Hence, tooth mobility varies from one tooth to the next and the classifications described above can only support approximate statements concerning mobility classes. Therefore, for the new simulation device, four mobility classes (MC) $0.15,0.30,0.6$ and 1.0 were introduced (Figure 5). The numerical values specify the horizontal movement of the abutment tooth at the defined measuring point in millimeters $(\mathrm{mm})$.

- MC $0.15 \rightarrow$ no increase in tooth mobility

- MC $0.30 \rightarrow$ slight tooth mobility

- MC $0.60 \rightarrow$ visible tooth mobility

- MC $1.0 \rightarrow$ high tooth mobility

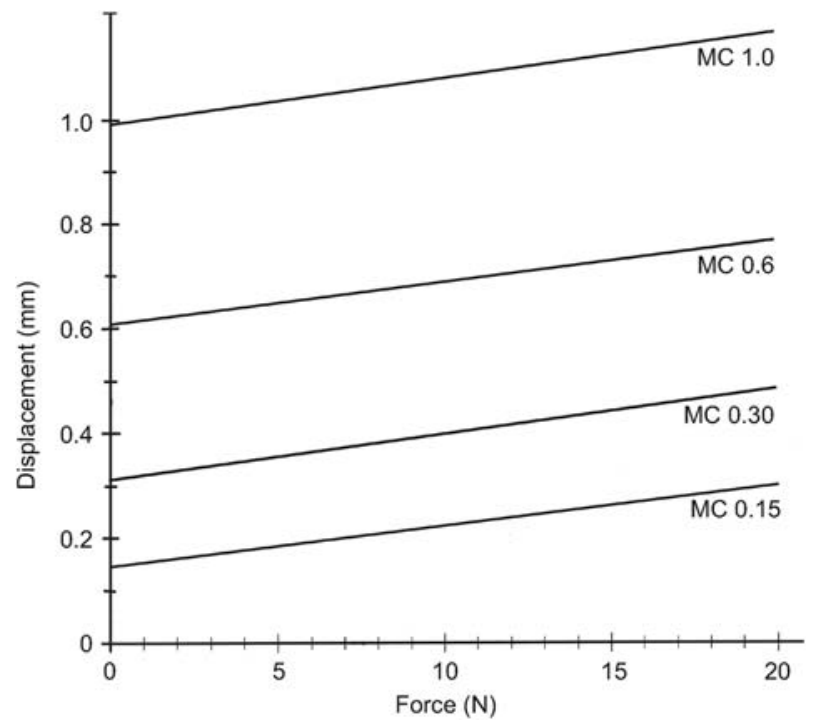

Figure 5 Movement on measurement point without initial mobility. Different mobility classes (MC) simulated by the simulation device. 
The measuring point for the determination of mobility was put $7 \mathrm{~mm}$ above the arresting plate. Thus, it is possible to determine mobility classes that are independent of tooth classes. The mobility classes MC describe the horizontal mobility of the abutment tooth at a distance of $7 \mathrm{~mm}$ above the arresting plate. The arresting plate corresponds to the cementoenamel junction; the distance of the measuring point to the arresting plate conforms to the averaged crown height of a molar. Thus, the crown length of different teeth loses its critical importance in in vitro tests. To set-up the mobility class for a tooth, its tooth class and the correct arresting plate have to be known. Every arresting plate (1-4) has its own calculated size for the mobility class (MC).

Through use of the mobility class MC (arresting plates 1-4) and the tooth classes, the test set-up of the simulation device can be described precisely (Figure 5).

\section{Curve of mobility}

The initial abutment tooth movement was simulated with silicone gaskets that surrounded the neck of the abutment tooth (Figure 6). This condensation crosslinking silicone (Xantropren L blau, Heraeus Kulzer GmbH, Hanau, Germany) provides the best results to simulate the initial abutment tooth mobility.

To adjust the motion curve of the silicone gaskets (Figure 7) to the initial motion curve of a tooth (Figure 1), the gaskets are chamfered (Figure 8).

The basic shape of the gasket consists of a square of $2 \mathrm{~mm} \times 2 \mathrm{~mm}$. The variation of the gaskets lies in the size of the chamfers. Gasket 1 is not chamfered, gasket 2 has a chamfer of $1 \mathrm{~mm} \times 1 \mathrm{~mm}$, and gasket 3 has a chamfer of $1 \mathrm{~mm} \times 1.75 \mathrm{~mm}$ (Figure 8).

With the use of these three forms of gaskets, we obtain the best simulation of the initial mobility curves of all tooth classes.

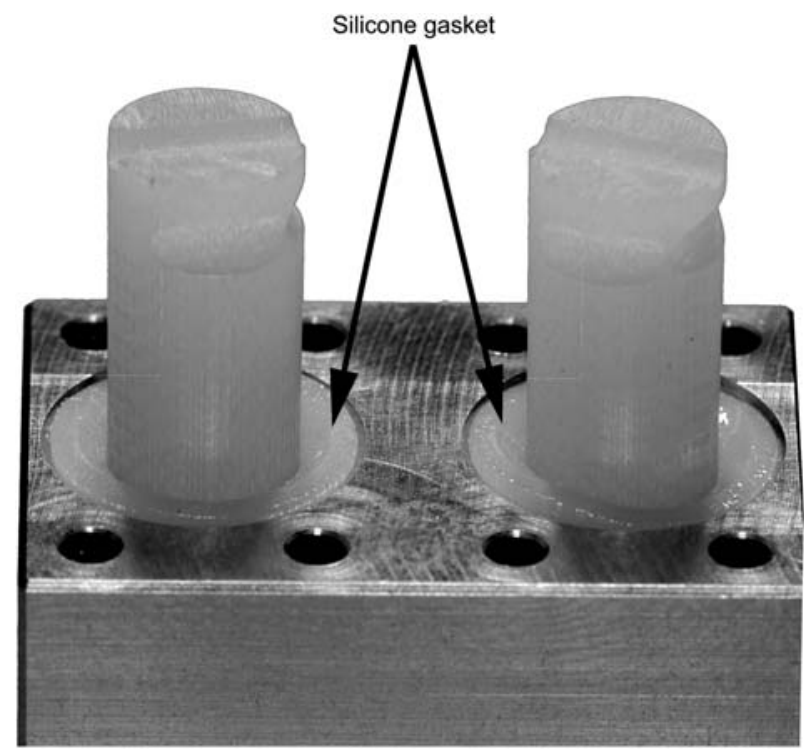

Figure 6 Abutment tooth surrounded with silicone gasket.

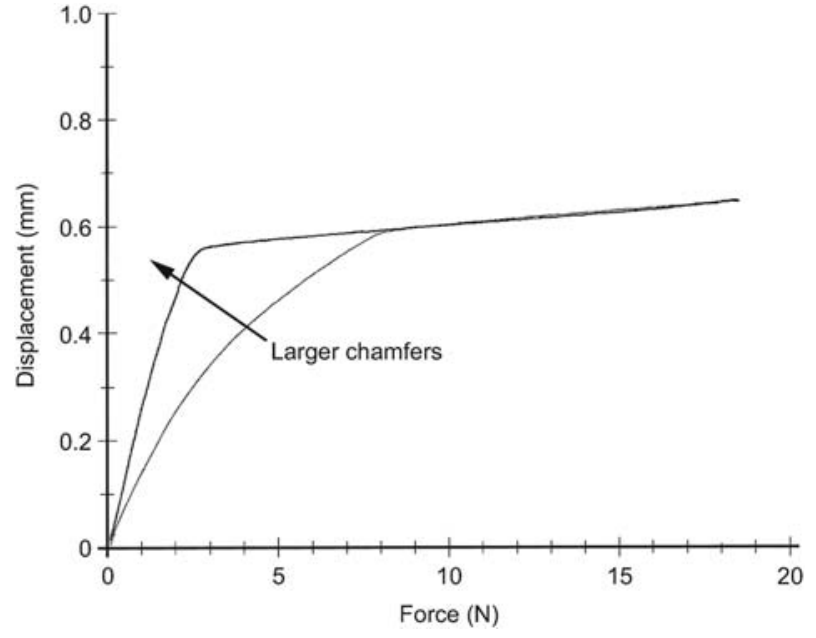

Figure 7 Influence of the gasket chamfer on the initial abutment tooth mobility curve with MC 1.0.

\section{Anti-rotation lock}

Through the arresting plates, the horizontal movement of the abutment tooth is restricted. Owing to the circular abutment tooth profile of incisors and canines, vertical rotation of the abutment tooth cannot be restricted during mobility simulations (rotational symmetry). To prevent rotation, certain areas of the ball under the abutment tooth and of the bearing shells are flattened. By varying the distance of the flat spots to the pivotal point of the abutment tooth, it is possible to limit the range and angle of rotation to a certain value. When the abutment tooth rotates beyond a certain angle the lock prevents any further rotation. Because there are no exact data on the extent of rotational movement in teeth, the rotation angle was limited to a maximum of $10^{\circ}$.

\section{Combined device}

When all subassembly groups of the simulation device (Figure 2) are assembled, it is possible to simulate the tooth mobility curve of natural teeth [11, 17, 22, 25, 34, 44] (Figure 1) with different mobilities in repetitious accuracy. To regulate the mobility classes and the initial tooth mobility curve of the simulation device it has to be assembled with the components described in Table 1.

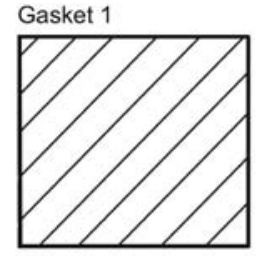

$2 \mathrm{~mm} \times 2 \mathrm{~mm}$

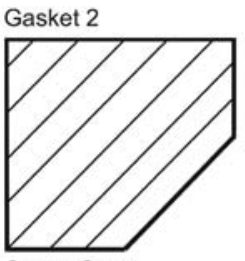

$2 \mathrm{~mm} \times 2 \mathrm{~mm}$ Chamfer $1 \mathrm{~mm} \times 1 \mathrm{~mm}$

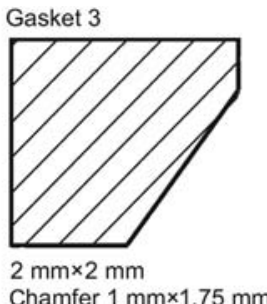

Figure 8 Gasket geometries (cross-sectional area). 
Table 1 Combination of tooth class, arresting plates and type of gasket to obtain acceptable mobility curves for different mobility classes.

\begin{tabular}{llll}
\hline Tooth class & $\begin{array}{l}\text { Mobility class } \\
\text { (MC) }\end{array}$ & $\begin{array}{l}\text { Arresting plate } \\
\text { (type) }\end{array}$ & $\begin{array}{l}\text { Gasket } \\
\text { (type) }\end{array}$ \\
\hline Incisors, canines & 0.15 & 1 & 1 \\
& 0.30 & 2 & 1 \\
& 0.60 & 3 & 1 \\
Premolar & 1.00 & 4 & 2 \\
& 0.15 & 1 & 3 \\
& 0.30 & 2 & 3 \\
Molar & 0.60 & 3 & 2 \\
& 1.00 & 4 & 2 \\
& 0.15 & 1 & 1 \\
& 0.30 & 2 & 1 \\
& 0.60 & 3 & 2 \\
\hline
\end{tabular}

\section{Discussion}

The simulation device developed at LMU overcomes the problems of other mobility devices.

In other simulation devices the roots of the abutment teeth are surrounded with rubber, silicone or other elastic materials. The thickness of the surrounding material can vary considerably and cannot be accurately determined, making it impossible to replicate mobility curves. The Young's modulus of the surrounding material is also of great importance. If the Young's modulus is too high, mobility is restricted. If it is low, an increase in lateral mobility and in apical deformability will result in too high overall mobility. The depth up to which the abutment tooth is embedded can vary between abutment teeth and thus influence mobility. In most mobility devices the root of the tooth shape is not sufficiently considered, so that the pivotal points of the devices do not correspond to that of the real tooth, and tooth mobility in the devices differs from that of natural teeth. To compare tests, abutment tooth geometries must be standardized. In particular, the use of natural teeth can lead to great variations in mobility simulations.

The LMU tooth mobility simulation device attempts to avoid all these disadvantages. The introduction of mobility classes (MC) with precisely defined mobility values achieves independence from subjectively assigned degrees of tooth mobility. Abutment tooth mobility is clearly defined by the mobility classes, thus there can be no discrepancies between different test sequences. With the introduction of different tooth class devices, each with standardized base geometries, an improvement of the reproducibility of curves, compared to other mobility devices, has been achieved. This improvement was due to the consideration of the root pivotal points for each of the tooth classes (Figure 3). Furthermore, the mobility curve of the LMU simulation device manages to approximate physiological tooth mobility with the use of suitable materials. The high degree of standardization in the LMU simulation device means that only a few specifications (tooth class, mobility class and the point of applied force) are needed to unambiguously describe the experimental set- up. In examinations where tooth mobility is a decisive factor, the use of the LMU simulation device contributes to an improvement of predictions.

Furthermore, the LMU simulation device can also improve numerical simulation models of prosthetic restorations. By comparing the results of the experimental device with those of the numerical simulation model, an optimization of the material properties of the latter can be achieved leading to a better description of the stress distribution in prosthetic restorations and an improvement in lifetime prediction.

\section{References}

[1] Ash MM. Wheeler's atlas of tooth form. 5th ed. Philadelphia, PA: Elsevier Health Sciences 1984.

[2] Avallone E, Baumeister T, Sadegh A. Mark's standard handbook for mechanical engineers. New York: McGraw-Hill 2007.

[3] Behr M, Hindelang U, Rosentritt M, Lang R, Handel G. Comparison of failure rates of adhesive-fixed partial dentures for in vivo and in vitro studies. Clin Oral Investig 2000; 4: 25-30.

[4] Beuer F, Steff B, Naumann M, Sorensen JA. Load-bearing capacity of all-ceramic three-unit fixed partial dentures with different computer-aided design (CAD)/computer-aided manufacturing (CAM) fabricated framework materials. Eur J Oral Sci 2008; 116: 381-386.

[5] Bieniek KW, Marx R. The mechanical loading capacity of new all-ceramic crown and bridge materials. Schweiz Monatsschr Zahnmed 1994; 104: 284-289.

[6] Burstone CJ. Application of bioengineering to clinical orthodontics. In: Graber T, Vanardall R, Vig K, editors. Orthodontics. 4th ed. St Louis, MO: Mosby Elsevier 2005: 293-331.

[7] Dornhofer R, Arnetzl GV, Koller M, Arnetzl G. Comparison of the static loading capacity of all-ceramic bridge frameworks in posterior teeth using three hard core materials. Int J Comput Dent 2007; 10: 315-328.

[8] Fischer M. Festigkeitsprüfung an dreigliedrigen VollkeramikFrontzahnbrücken auf einem neuentwickelten Prüfmodell. Tübingen: Dissertation 2002.

[9] Fujita T. Textbook of dental anatomy. 22nd ed. Tokyo: Kanehara 1995.

[10] Gladwin M, Bagby M. Clinical aspects of dental materials: theory, practice and cases. Philadelphia, PA: Williams \& Wilkins 2004.

[11] Graf H. Physiology of tooth mobility. Dtsch Zahnärztl Z 1980; 35: 678-679.

[12] Graf M, Oettli M. Mathematics and physics formulary. Zurich: Compendio 2006.

[13] Grebe H. In-vitro Biegefestigkeit von vollkeramischen im Vergleich zu metallkeramischen Seitenzahnbrücken unter Berücksichtigung der Lagerart. Berlin: Dissertation 1993.

[14] Grimm T. User's guide to rapid prototyping. Dearborn: Society of Manufacturing Engineers 2004.

[15] Hall W. Critical decisions in periodontology. London: BC Decker Inc 2003.

[16] Heraeus. Der passgenaue Dentalguss. Hanau: Heraeus Edelmatalle GmbH 1999.

[17] Hinterkausen M, Bourauel C, Siebers G, Haase A, Drescher D, Nellen B. In vitro analysis of the initial tooth mobility in 
a novel optomechanical set-up. Med Eng Phys 1998; 20: 40-49.

[18] Kamrani A, Nasr E. Rapid prototyping: theory and practice. New York: Springer 2006.

[19] Kappert HF, Knode H, Schultheiss R. Strength of the InCeram system under mechanical loads and thermocycling in artificial saliva. Dtsch Zahnärztl Z 1991; 46: 129-131.

[20] Kolbeck C, Behr M, Rosentritt M, Handel G. Fracture force of tooth-tooth- and implant-tooth-supported all-ceramic fixed partial dentures using titanium vs. customised zirconia implant abutments. Clin Oral Implants Res 2008; 19: 10491053.

[21] Körber K. Zahnärztliche Prothetik. Stuttgart: Georg Thieme Verlag 1985.

[22] Lehmann KM, Hellwig E. Einführung in die restaurative Zahnheilkunde. München: Urban \& Schwarzenberg 1998.

[23] Mante FK, Brantley WA, Dhuru VB, Ziebert G. Fracture toughness of high alumina core dental ceramics: the effect of water and artificial saliva. Int J Prosthodont 1993; 6: 546552.

[24] Marxkors R, Meiners H. Taschenbuch der zahnärztlichen Werkstoffkunde. München: Carl Hanser Verlag 2005.

[25] Niedermeier W. Periodontometry - a new method for the measurement and analysis of tooth mobility. III. Physiologic and pathologic tooth mobility. Dtsch Zahnärztl Z 1988; 43: 173-181.

[26] Nield-Gehrig J, Willmann E. Foundations of periodontics for the dental hygienist. Baltimore, MD: Lippincott Williams \& Wilkins 2002.

[27] Norton L, Burstone CJ. The biology of tooth movement. Boca Raton, FL: CRC Press Inc 1988.

[28] O'Leary T. Indices for measurement of tooth mobility in clinical studies. J Periodontal Res Suppl 1974; 14: 94-105.

[29] Pallis K, Griggs JA, Woody RD, Guillen GE, Miller AW. Fracture resistance of three all-ceramic restorative systems for posterior applications. J Prosthet Dent 2004; 91: 561-569.

[30] Pospiech P, Rountree P, Unsöld F, Rammelsberg P. In-vitroinvestigations on the fracture strength of all-ceramic posterior bridges of Empress 2. J Dent Res 1999; 307: 1609.

[31] Powers M, Wataha C. Dental materials: properties and manipulation. Oxford: Mosby Elsevier 2007.
[32] Raigrodski AJ, Chiche GJ. All-ceramic fixed partial dentures. Part I: in vitro studies. J Esthet Restor Dent 2002; 14: 188-191.

[33] Rateitschak KH, Rateitschak ERM, Wolf HF. Parodontologie. Stuttgart: Georg Thieme Verlag 1989.

[34] Richter EJ. The importance of test conditions in scientific experiments, as demonstrated by the example of tooth mobility. Dtsch Zahnärztl Z 1985; 40: 404-409.

[35] Rosentritt M, Kolbeck C, Ries S, Gross M, Behr M, Handel G. Zirconia resin-bonded fixed partial dentures in the anterior maxilla. Quintessence Int 2008; 39: 313-319.

[36] Rosentritt M, Leipold A, Lang R. Regensburger Kausimulator-Apparatur zur Simulation des Kauorgans. Materialprüfung 1997; 39: 77.

[37] Sander FG. Biomechanik der Zahnbewegung. In: Dietrich P. Kieferorthopädie II. 4. Auflage. München, Jena: Elsevier Urban Fischer 2000: 85-101.

[38] Schneemann P. Belastbarkeit viergliedriger Seitenzahnbrücken aus hochfester Strukturkeramik. Hannover: Dissertation 2006.

[39] Thilander B, Rygh P, Reitan K. Tissue reactions in orthodontics. In: Graber T, Vanardall R, Vig K, editors. Orthodontics. 4th ed. St Louis, MO: Mosby Elsevier 2005: 145-221.

[40] Tinschert J, Natt G, Mautsch W, Augthun M, Spiekermann $\mathrm{H}$. Fracture resistance of lithium disilicate-, alumina-, and zirconia-based three-unit fixed partial dentures: a laboratory study. Int J Prosthodont 2001; 14: 231-238.

[41] Tinschert J, Natt G, Hassenpflug S, Spiekermann H. Status of current CAD/CAM technology in dental medicine. Int $\mathbf{J}$ Comput Dent 2004; 7: 25-45.

[42] Vult von Steyern P. All-ceramic fixed partial dentures. Studies on aluminium oxide- and zirconiumdioxide-based ceramic systems. Swed Dent J Suppl 2005; 173: 1-69.

[43] Wilkins E, Wyche C. Clinical practice of the dental hygienist. Philadelphia, PA: Lippincott Williams \& Wilkins 2004.

[44] Yamane M, Yamaoka M, Hayashi M, Furutoyo I, Komori N, Ogiso B. Measuring tooth mobility with a no-contact vibration device. J Periodontal Res 2008; 43: 84-89.

Received November 30, 2009; accepted August 3, 2010; online first September 15, 2010 